\title{
EVALUASI PENGELOLAAN SAMPAH DI TERMINAL PURABAYA KOTA SURABAYA TAHUN 2017
}

Khairil Anam, Sri Mardoyo, Fitri Rokhmalia

\begin{abstract}
ABSTRAK
Terminal Purabaya adalah tempat-tempat umum yang terdiri dari kegiatan pelayanan penumpang atau barang dengan kendaraan bus atau angkutan umum, Terminal Purabaya terbesar di Jawa Timur, jumlah sampah yang dihasilkan setiap harinya rata-rata $14 \mathrm{~m}^{3}$ dengan rata-rata jumlah penumpang kedatangan 29.000 dan keberangkatan 28.300 orang setiap harinya, maka perlu mendapatkan pengawasan pengelolaan yang baik untuk mengantisipasi timbulnya dampak negatif terhadap lingkungan, dari hasil survei pendahuluan yang dilakukan di Terminal Purabaya dari aktifitas pengunjung, penumpang maupun pengelola dapat mempengaruhi jumlah sampah di Terminal Purabaya, penelitian ini bertujuan untuk mengukur jumlah sampah, melakukan observasi mengenai pengelolaan sampah, dan mengevaluasi pengelolaan sampah di Terminal Purabaya menggunakan analisis SWOT.

Penelitian ini merupakan penelitian deskriptif kualitatif dengan menggambarkan fakta yang ada terkait pengelolaan sampah di Terminal Purabaya. Sampel dalam penelitian ini mengambil orang yang dianggap mengetahui permasalahan yang diteliti yaitu pengelola, petugas kebersihan, pengawas petugas kebersihan, dan Kepala Terminal Purabaya. Data yang diperoleh selanjutnya dianalisis SWOT.

Dari hasil penelitian, maka didapat hasil timbulan sampah perhari di Terminal Purabaya $4.870,28 \mathrm{Kg} / \mathrm{hari}$, dan penilaian pengelolaan sampah di Terminal Purabaya pada tahap penimbulan $88 \%$, pengumpulan $77 \%$, penyimpanan sampah sementara $95 \%$, dan pengangkutan ke TPA $100 \%$, dari semua tahap pengelolaan sampah dapat dikategorikan baik.

Pada analisis SWOT didapat beberapa strategi, antara lain: (1) Terminal Purabaya merupakan Terminal terbesar, yang mana terkait pengelolaan sampah telah bekerja sama dengan DKP atau dinas terkait. Sumber daya manusia (SDM) petugas kebersihan di Terminal Purabaya sudah cukup; (2) Meningkatkan wawasan petugas kebersihan dalam melaksanakan tugasnya; (3) Perlu adanya koordinasi antara pihak Terminal dengan tokoh masyarakat; (4) Perbaikan dan peningkatan sarana prasarana; (5) Meningkatkan wawasan masyarakat / pengunjung Terminal dalam hal pentingnya membuang sampah pada tempatnya.
\end{abstract}

Kata kunci : SWOT, Analisis pengelolaan sampah.

\section{PENDAHULUAN}

Indonesia merupakan Negara berkembang yang menghadapi masalah serius dalam pengelolaan sampah, pada Tahun 2011 diperkirakan jumlah sampah di Indonesia mencapai 80.000 ton setiap harinya dari 230 Kota, dan sampah plastik diperkirakan akan mencapai 14 persen dari total sampah yang ada, namun hanya 34.000 ton sampah yang terangkut dan dikelola dengan layak. Sebagian besar sampah yang tidak terangkut dibakar secara terbuka (Prakarsa, 2013).

Berdasarkan Peraturan Pemerintah No 74 Tahun 2014, Terminal adalah prasarana transportasi jalan untuk keperluan memuat dan menurunkan orang /atau barang.
Terminal merupakan salah satu lokasi yang memiliki potensi produksi sampah yang cukup besar, produksi sampah yang dihasilkan dari aktifitas pengunjung dan pengelola Terminal seringkali melebihi daya tampung prasarana persampahan yang tesedia. Timbulan sampah yang terjadi akibat ketidakseimbangan produksi sampah dan infrastruktur persampahan menyebabkan munculnya timbulan sampah (Selintung dkk, 2015).

Dari hasil pengkajian kepustakaan yang dilakukan, ditemukan bahwa untuk memastikan agar kegiatan pengelolaan sampah dapat mewujudkan pelaksanaan kegiatan pengelolaan itu sendiri, maka perlu di identifikasi berbagai faktor yang 
mempengaruhi kegiatan pengelolaan sampah, baik faktor pendukung maupun faktor penghambat. Salah satu metode yang dapat digunakan adalah metode analisis SWOT (Abdul, 2012).

Dari hasil survei pendahuluan yang dilakukan di Terminal Purabaya dari aktifitas pengunjung, penumpang maupun pengelola terminal juga dapat menghasilkan sampah yang dapat mempengaruhi jumlah timbulan sampah di Terminal Purabaya, selain itu tempat penampungan sementara (TPS) di Terminal Purabaya juga menampung sampah dari warga sekitar Terminal, sehingga menigkatkan jumlah sampah di Terminal Purabaya.

\section{METODE PENELITIAN}

Jenis penelitian ini adalah deskriptif kualitatif yang dilakukan dengan tujuan utama untuk menggambarkan tentang pengelolaan sampah di Terminal Purabaya Kota Surabaya.

Objek penelitian ini terdiri dari aspek teknis yang meliputi penimbulan, pengumpulan, penyimpanan sampah sementara, dan pengangkutan ke TPA. Aspek non teknis yang meliputi pengorganisasian, ketenagaan, pembiayaan, serta jumlah sampah.

Teknik pengumpulan data dalam penelitian ini adalah wawancara dengan petugas pelaksana, observasi dan penilaian pengelolaan sampah, dan pengukuran jumlah sampah.

Analisis diawali penelaahan hasil penelitian bersumber dari pengumpulan data observasi dan wawancara, kemudian ditentukan menggunakan analisis SWOT.

\section{HASIL DAN PEMBAHASAN}

Jumlah Sampah di TPS Terminal Purabaya per hari

Tabel 1

JUMLAH TIMBULAN SAMPAH SELAMA 7 HARI DI TERMINAL PURABAYA KOTA SURABAYA TAHUN 2017

\begin{tabular}{|c|c|c|}
\hline No & Hari ke & Jumlah Sampah (kg) \\
\hline 1. & Pertama & 4.810 \\
\hline 2. & Kedua & 4.920 \\
\hline 3. & Ketiga & 5.136 \\
\hline 4. & Keempat & 4.984 \\
\hline 5. & Kelima & 4.870 \\
\hline 6. & Keenam & 4.695 \\
\hline \multirow[t]{2}{*}{7.} & Ketujuh & 4.677 \\
\hline & Rata - rata & $4.870,28$ \\
\hline
\end{tabular}

Berdasarkan tabel 1 dapat diketahui bahwa jumlah sampah rata-rata $4.870,28$ $\mathrm{kg} /$ hari.

Pengukuran ini dilakukan pada tanggal 916 Juni 2017. Pengukuran ini dilakukan 7 hari berturut- turut untuk mengetahui floktuasi yang ada sesuai dengan SNI 19-3964-1994.

Jumlah sampah dapat dipengaruhi atau disebabkan oleh aktifitas pengunjung, penumpang, dan pengelola Terminal. Pengangkutan sampah dilakukan oleh petugas kebersihan $1 \times 24$ jam. 


\section{Penilaian pengelolaan sampah di Terminal Purabaya Tahap Penimbulan}

Tabel 2

HASIL PENILAIAN PENGELOLAAN SAMPAH PADA TAHAP PENIMBULAN DI TERMINAL PURABAYA KOTA SURABAYA TAHUN 2017

\begin{tabular}{llcccc}
\hline No & Variabel & Bobot & Skore Max & Skore Hasil & \% \\
\hline 1. & Tempat sampah & 20 & 1000 & 900 & $90 \%$ \\
\hline 2. & $\begin{array}{l}\text { Kondisi tempat } \\
\text { sampah }\end{array}$ & 15 & 750 & 645 & $86 \%$ \\
\hline & Jumlah & 35 & 1750 & 1545 & $88 \%$ \\
\hline
\end{tabular}

Dari tabel 2 dapat diketahui bahwa tahap penimbulan meliputi penilaian tempat sampah dan kondisi tempat sampah memperoleh persentase $88 \%$ kriteria baik. Hal yang masih kurang ditemukan adanya tempat sampah yang belum dilengkapi sampah terpisah antara basah dan kering, namun Terminal Purabaya sudah mulai melengkapi tempat sampah terpisah sesuai Peraturan Daerah Kota
Surabaya No 5 Tahun 2014 yang membagi tempat menjadi 5 jenis, antara lain: sampah B3, sampah mudah terurai, sampah dapat digunakan kembali, sampah dapat di daur ulang, dan sampah lainnya.

Kondisi tempat sampah masih ada yang ditemukan belum dilengkapi penutup, dan masih ada tempat sampah yang mudah berkarat (Damanhuri, 2010).

\section{Tahap Pengumpulan}

Tabel 3

HASIL PENILAIAN PENGELOLAAN SAMPAH PADA TAHAP PENGUMPULAN DI TERMINAL PURABAYA KOTA SURABAYA TAHUN 2017

\begin{tabular}{llcccc}
\hline No & \multicolumn{1}{c}{ Variabel } & Bobot & Skore Max & Skore Hasil & \% \\
\hline 1. & Pengumpulan sampah & 15 & 750 & 600 & $80 \%$ \\
\hline 2. & $\begin{array}{l}\text { Kondisi alat angkut } \\
\text { pengumpul sampah }\end{array}$ & 20 & 1000 & 740 & $74 \%$ \\
\hline & Jumlah & 35 & 1750 & 1340 & $77 \%$ \\
\hline
\end{tabular}

Dari tabel 3 dapat diketahui bahwa tahap pengumpulan meliputi penilaian pengumpulan sampah, dan kondisi alat angkut pengumpul sampah memperoleh persentase $77 \%$ dengan kriteria baik. Pengambilan sampah yang dilakukan Terminal Purabaya minimal 1 hari sekali sudah sesuai dengan Keputusan Menteri
Pekerjaan Umum RI No 03/PRT/M/2013, dan pada penilaian kondisi alat angkut pengumpul sampah masih kurang, karena pada saat dilakukan observasi di lapangan masih terdapat alat angkut yang rusak, tidak kedap air, dan sulit dibersihkan.

\section{Tahap Penyimpanan Sampah Sementara}

Tabel 4

HASIL PENILAIAN PENGELOLAAN SAMPAH PADA TAHAP PENYIMPANAN SAMPAH SEMENTARA DI TERMINAL PURABAYA KOTA SURABAYA TAHUN 2017

\begin{tabular}{llcccc}
\hline No & \multicolumn{1}{c}{ Variabel } & Bobot & Skore Max & Skore Hasil & \% \\
\hline 1. & TPS & 10 & 500 & 500 & $100 \%$ \\
\hline 2. & $\begin{array}{l}\text { Kondisi kontainer } \\
\text { pengangkut sampah }\end{array}$ & 10 & 500 & 450 & $90 \%$ \\
\hline & Jumlah & 20 & 1000 & 950 & $95 \%$ \\
\hline
\end{tabular}

Dari tabel 4 dapat diketahui bahwa tahap penyimpanan sampah sementara meliputi penilaian TPS dan kondisi kontainer pengangkut sampah memperoleh persentase $95 \%$ dengan kriteria baik. Pada tahap ini kondisi TPS sudah jauh 
dari bangunan Terminal, dan tidak menjadi tempat perindukan vektor karena dibuang setiap hari. Tidak hanya kondisi TPS, kondisi kontainer pengangkut sampah juga baik, karena sudah dilengkapi penutup, kuat, dan mudah dipindahkan (Damanhuri dkk, 2010).

\section{Tahap Pengangkutan ke TPA}

Tabel 5

HASIL PENILAIAN PENGELOLAAN SAMPAH PADA TAHAP PENGANGKUTAN

KE TPA DI TERMINAL PURABAYAKOTA SURABAYA TAHUN 2017

\begin{tabular}{llcccc}
\hline No & Variabel & Bobot & Skore Max & Skore Hasil & $\mathbf{\%}$ \\
\hline 1. & Alat angkut & 10 & 500 & 500 & $100 \%$ \\
\hline & Jumlah & 10 & 500 & 500 & $100 \%$ \\
\hline
\end{tabular}

Dari tabel 5 dapat diketahui bahwa tahap pengangkutan ke TPA memperoleh persentase $100 \%$ dengan kriteria baik. Pengakutan ke TPA dilakukan 1 kali sehari, dan tidak terdapat sampah yang tersisa. Kegiatan tersebut sudah sesuai dengan persyaratan alat angkut (Damanhuri dkk, 2010).

\section{Evaluasi pengelolaan sampah menggunakan analisis SWOT}

Pada evaluasi pengelolaan sampah menggunakan analisis SWOT diperlukan pertama kali informasi/wawancara dari stakeholder yang terkait pengelolaan sampah di Terminal Purabaya, dari beberapa aspek wawancara yang sudah dilakukan dapat ditarik kesimpulan beberapa kekuatan, kelemahan, peluang, dan ancaman yang telah tercantum di tabel bawah ini

Tabel 6

FAKTOR STRATEGI EKSTERNAL (EFAS) DILIHAT DARI PELUANG DAN ANCAMAN

\begin{tabular}{llcccc}
\hline No & \multicolumn{1}{c}{ Peluang } & Bobot & Relatif & Rating & Score \\
\hline 1. & $\begin{array}{l}\text { Perbaikan/pembenahan rumah } \\
\text { kompos agar dapat beroperasi }\end{array}$ & 4 & 0.150 & 3.2 & 0.48 \\
\hline 2. & $\begin{array}{l}\text { Dilakukan pemantauan oleh DKP dan } \\
\text { DISHUB }\end{array}$ & 3.8 & 0.143 & 3 & 0.43 \\
\hline 3. & $\begin{array}{l}\text { Bisa mengumpulkan petugas } \\
\text { kebersihan, untuk pemberian } \\
\text { penyuluhan terkait sampah. }\end{array}$ & 3.8 & 0.143 & 2.9 & 0.41 \\
\hline 4. & $\begin{array}{l}\text { Jika rumah kompos beroperasi, dapat } \\
\text { mengurangi jumlah sampah }\end{array}$ & 4.3 & 0.162 & 3.3 & 0.53 \\
\hline 5. & $\begin{array}{l}\text { Sampah kering seperti botol plastik, } \\
\text { bisa dijual oleh petugas kebersihan }\end{array}$ & 3.9 & 0.147 & 3.1 & 0.45 \\
\hline$\quad \begin{array}{l}\text { Total } \\
\text { No }\end{array}$ & 19.8 & 0.741 & & 2.3 \\
\hline Ancaman & Bobot & Relatif & Rating & Score \\
\hline terhadap kebersihan & 3.5 & 0.131 & 2.9 & 0.38 \\
\hline $\begin{array}{l}\text { Bertambahnya tahun, jumlah sampah } \\
\text { makin banyak, dikarenakan dengan } \\
\text { salah satu faktornya bertambahnya } \\
\text { jumlah pengunjung dan jumlah } \\
\text { penduduk sekitar Terminal Purabaya } \\
\text { yang akan membuang sampahnya di } \\
\text { Terminal Purabaya. }\end{array}$ & 3.3 & 0.124 & 2.8 & 0.35 \\
\hline $\begin{array}{l}\text { Total } \\
\text { Total Bobot x Score untuk } \\
\text { External Faktor }\end{array}$ & 26.6 & 1.00 & & 3.03 \\
\hline
\end{tabular}


Berdasarkan hasil dari tabel 6 dapat diketahui bahwa posisi eksternal mendapat total nilai 3.03. Total nilai skore peluang 2.3, total nilai skore ancaman 0.73 . Maka apabila selisi untuk menentukan sumbu $Y$ yaitu 1.57 .

Tabel 7

FAKTOR STRATEGI INTERNAL (IFAS) DILIHAT DARI KEKUATAN DAN KELEMAHAN

\begin{tabular}{|c|c|c|c|c|c|}
\hline No & Kekuatan & Bobot & Relatif & Rating & Score \\
\hline 1. & $\begin{array}{l}\text { Terminal Purabaya merupakan } \\
\text { terminal terbesar di Jawa Timur }\end{array}$ & 3.9 & 0.115 & 2.5 & 0.29 \\
\hline 2. & $\begin{array}{l}\text { Terminal Purabaya mempunyai rumah } \\
\text { kompos }\end{array}$ & 4.4 & 0.130 & 3.2 & 0.42 \\
\hline 3. & $\begin{array}{l}\text { Sumber daya manusia (SDM) petugas } \\
\text { kebersihan cukup }\end{array}$ & 4 & 0.118 & 2.8 & 0.33 \\
\hline 4. & Sudah terbentuk kelompok kerja & 4 & 0.118 & 2.6 & 0.31 \\
\hline \multirow[t]{2}{*}{5.} & $\begin{array}{l}\text { Kerja sama dengan DKP terkait } \\
\text { pengelolaan sampahnya }\end{array}$ & 4.3 & 0.127 & 2.6 & 0.33 \\
\hline & Total & 20.6 & 0.608 & & 1.68 \\
\hline No & Kelemahan & Bobot & Relatif & Rating & Score \\
\hline 1. & $\begin{array}{l}\text { Kurangnya peralatan kebersihan, } \\
\text { seperti gerobak }\end{array}$ & 3.5 & 0.104 & 3.4 & 0.35 \\
\hline 2. & $\begin{array}{l}\text { Masih ada tempat sampah yang } \\
\text { belum dilengkapi penutup }\end{array}$ & 3.2 & 0.095 & 3.2 & 0.30 \\
\hline 3. & $\begin{array}{l}\text { Jika ingin membeli peralatan harus } \\
\text { konfirmasi ke DKP dan DISHUB, harus } \\
\text { menunggu persetujuan }\end{array}$ & 3.3 & 0.098 & 3 & 0.29 \\
\hline \multirow[t]{3}{*}{4.} & Belum dilakukan pemilahan sampah & 3.2 & 0.095 & 3.1 & 0.29 \\
\hline & Total & 13.2 & 0.392 & & 1.23 \\
\hline & $\begin{array}{l}\text { Total Bobot x Score untuk } \\
\text { Internal Faktor }\end{array}$ & 33.8 & 1.00 & & 2.91 \\
\hline
\end{tabular}

Berdasarkan hasil tabel 7 dapat diketahui bahwa posisi internal mendapat total nilai 2.91. Total nilai kekuatan 1.68, total kelemahan 1.23. Maka apabila selisi untuk menentukan sumbu $X$ yaitu 0.45 .

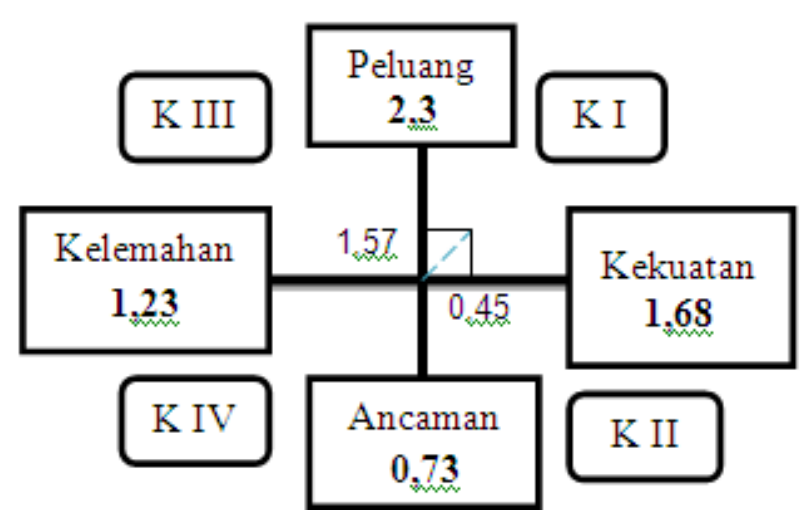

Gambar 1. Diagram SWOT Hasil Analisis 
Dari gambar 1 diagram analisis SWOT dapat di tentukan berada pada kuadran I yaitu mendukung strategi agresif (Rangkuti, 2015)

Dari analisis faktor eksternal dan analisis faktor internal dipadukan dalam matrik SWOT, untuk menciptakan sebuah strategi, dan di dapatkan alternative strategi pengelolaan sampah sesuai dengan kondisi lingkungan internal dan eksternal pengelolaan sampah sebagai berikut:

a. Terminal Purabaya merupakan Terminal terbesar, yang mana terkait pengelolaan sampah telah

bekerja sama dengan DKP atau dinas terkait. Sumber daya manusia (SDM) petugas kebersihan di Terminal Purabaya sudah cukup.

b. Meningkatkan wawasan petugas kebersihan dalam melaksanakan tugasnya.

c. Perlu adanya koordinasi antara pihak Terminal dengan tokoh masyarakat.

d. Perbaikan dan peningkatan sarana prasarana.

e. Meningkatkan wawasan masyarakat / pengunjung Terminal dalam hal pentingnya membuang sampah pada tempatnya.

\section{Kesimpulan}

1. Jumlah sampah yang dihasilkan dari aktifitas Terminal Purabaya rata-rata $4.870,28 \mathrm{~kg} / \mathrm{hari}$.

2. Hasil penilaian pengelolaan sampah di Terminal Purabaya pada tahap penimbulan $88 \%$, pengumpulan $76 \%$, penyimpanan sampah sementara $95 \%$, dan pengangkutan ke TPA $100 \%$. Dari semua tahap pengelolaan sampah dapat dikategorikan baik.

3. Evaluasi pengelolaan sampah di Terminal Purabaya, menggunakan analisis SWOT.
a. Hasil penelitian dengan
menggunakan matrik IFAS menunjukkan sumbu $X$ yaitu 0,45 dan matrik EFAS menunjukkan sumbu $Y$ yaitu 1,57, setelah menyimpulkan dari analisis SWOT, dapat di tentukan berada pada kuadran I yaitu mendukung strategi agresif.

b. Dari hasil matrik SWOT diatas menghasilkan beberapa alternatif strategi pengelolaan sampah, antara lain:

1) Terminal Purabaya merupakan Terminal terbesar, yang mana terkait pengelolaan sampah telah bekerja sama dengan DKP atau dinas terkait. Sumber daya manusia (SDM) petugas kebersihan di Terminal Purabaya sudah cukup.

2) Meningkatkan wawasan petugas kebersihan dalam melaksanakan tugasnya.

3) Perlu adanya koordinasi antara pihak Terminal dengan tokoh masyarakat.

4) Perbaikan dan peningkatan sarana prasarana.

5) Meningkatkan wawasan masyarakat / pengunjung Terminal dalam hal pentingnya membuang sampah pada tempatnya.

\section{Saran}

1. Bagi Terminal Purabaya
a. Meningkatkan sarana dan prasarana untuk menunjang kinerja yang maksimal, yang masih kurang. khususnya gerobak sampah
b. Sebaiknya dengan adanya rumah kompos, cepat difungsikan untuk mengurangi jumlah sampah yang ada.
c. Perlu adanya komunikasi yang baik antara petugas kebersihan dan pengelola Terminal Purabaya.

2. Bagi Masyarakat

Dapat dijadikan ilmu pengetahuan bagi masyarakat tentang evaluasi pengelolaan sampah.

3. Bagi Peneliti Lain

Dapat dijadikan sebagai sumber informasi atau bahan masukan bagi peneliti lain yang akan melakukan penelitian lanjutan, mengenai evaluasi pengelolaan sampah. 


\section{DAFTAR PUSTAKA}

Abdul, F, 2012. Analisis SWOT tentang pengelolaan sampah di kawasan Pemukiman Suku Bajo Torosiaje Kecamatan Popayato Kabupataen Pohuwato.

Damanhuri dkk, 2010. Pengelolaan Sampah.Bandung. Diktat kuliah.

Keputusan Menteri Pekerjaan Umum RI No 03 Tahun 2013 tentang Penyelenggaraan Prasarana dan Sarana Persampahan Dalam Penanganan Sampah Rumah Tangga dan Sampah Sejenis Sampah Rumah Tangga.

Manajemen Persampahan. Jurnal Prakarsa Infrastruktur Indonesia. Edisi 15 Oktober 2013.
Peraturan Menteri Dalam Negeri No 33 Tahun 2010 tentang Pedoman Pengelolaan Sampah.

Peraturan Pemerintah No 74 Tahun 2014 tentang Angkutan Jalan.

Peraturan Daerah Kota Surabaya No 5 Tahun 2014 tentang Pengelolaan Sampah dan Kebersihan di Kota Surabaya.

Rangkuti, F, 2015. Teknik Membedah Kasus Bisnis Analisis SWOT. Jakarta, PT Gramedia Pustaka Utama.

Selintung, M., Zubair, A., Fuadi, F. 2015. Pengelolaan Sampah di Terminal Regional Daya Makassar.

SNI 19-3964-1994 tentang Metode pengambilan dan pengukuran contoh timbulan dan komposisi sampah perkotaan. 